\title{
Some Ideas about the Reformation of Intensive Reading Teaching
}

\author{
Tang TANG
}

\author{
Beijing Wuzi University, Fuhe Street No.1, Tongzhou District, Beijing, China, 101149 \\ Email: tangtang@bwu.edu.cn
}

Keywords: Intensive reading, Language teaching reformation, Teaching strategies.

\begin{abstract}
English teaching reformation is a tendency is ESL (English as the Second Language) learning. This paper aims to elaborate some of the teaching strategies in the course of Intensive Reading as one of the main and compulsory courses for students majoring in English. The analysis and implementation of "creating leaning situation", "emphasizing students' main role", "the techniques of asking questions" and "task-based teaching methods" are discussed in details in the paper, hoping it may give some insights for the reformation of ESL teaching as well as improve English teaching quality.
\end{abstract}

\section{Introduction}

English Intensive Reading, as a key course in the ESL faculty is confronted with a significant reformation process. How to perfect the teaching methods and improve the teaching quality has become a top challenge to be tackled. In the real class, it is essential to solve these problems as to what exact roles teachers shall play in classes, how to better play their roles and how to make more sufficient use of the class time. Hereby, some ideas are proposed about the reformation of Intensive Reading teaching in this paper, aiming to answer some of the questions.

\section{Creating Learning Situation to Bring Students’ Main Role as the Subject into Full Play}

Sun suggests that "the teaching process shall conform to student's cognitive regularities and enable students to be the cognitive subject" (Sun, 2013: 38). Intensive Reading teaching in universities/colleges shall be based on the thought of subject-oriented education to carry out teaching practices with students' participation as the subject In the process of education and teaching, how to foster students' learning interest and arouse their enthusiasm to participate becomes particularly important. Students' learning interest is produced and developed in a certain situation. In classroom teaching, teachers shall do everything possible to create teaching situations loved by students and imbue the class with a pleasant learning atmosphere so as to arouse students' learning interest and develop their thinking ability. Teachers shall "focus on guiding students in classroom teaching, create favorable learning situation corresponding to different teaching contents” (Sun, 2013: 80), enable them to discover and master the knowledge through observation, operation, discussion and thinking, and constantly encourage them to perform their role as the subject in learning.

\section{Proposal of Problems}

In the field of education where more and more emphasis is given on teaching students to learn today, "the influence of learning motivation, learning interest and other nonintellectual factors on students' learning has increasingly aroused widespread concern of the education sector" (Sun, 2013: 85). The English Intensive Reading teaching also prioritizes cultivation of students' interest in learning and mobilization of their enthusiasm as a key issue. Learning is a process for students to understand the objective world under the guidance of teachers. In this process, their learning tasks can only be successfully completed on the psychological premise of the presence of learning initiative, which is formed with the learning interest and reflected in their emotional status Confucius said, "the person who knows is not as good as the one who indulges in learning; the person who indulges in learning is not as good as the person who enjoys learning." Similarly, Einstein also 
remarked, "interest is the best teacher." Therefore, it has become most educators' common concern that how to stimulate students' learning interest and arouse their learning enthusiasm to develop their intelligence and ability in the teaching process. It has been proved by teaching practice that "the creation of classroom teaching situation is one of the most effective ways to fully mobilize the learning enthusiasm of students” (Watkins, 2005: 76).

\section{Explorations on Cultivating Students' Learning Interest Through Setting Teaching Situations in the Teaching Of English Intensive Reading: Creating Situations in the Introduction of a New Lesson to Stimulate Interest.}

At the beginning of a new lesson, teachers shall try every way to move students' emotion and arouse their psychological resonance, so as to develop their interest driven by their internal emotion.

Making use of the historical and cultural knowledge of English speaking countries. Since there are many episodes arising from the use of English, students can resonate with predecessors in their understanding of things through comprehension and perception. In this way, teachers can introduce the processes of generation and development of customs and cultures of such countries to students. For this language "which is still evolving, organically integrating teaching materials with language points can not only stimulate students' learning interest and deepen their understanding of knowledge" (Lou, 2012: 67), but also help enlighten their wisdom and develop their thinking.

Beginning a new lesson with things close to them and concerned by them will make students feel familiar, natural and funny, and be aware of the English knowledge that they can learn around. Therefore their interest in learning new things can be aroused once they shift the idea that English learning is no more than a monotonous and boring thing that they must to do for tests and examinations.

\section{Application of Task-based Teaching Method in English Intensive Reading Teaching}

The College English Intensive Reading focuses on improving students' ability to obtain and process information, and analyze and solve problems using English based on the further development of students' comprehensive language application ability. Special emphasis is given to improving their ability to think and express in English, and to forming cross-cultural communication consciousness and the basic cross-cultural communication ability, further broadening their international horizon.

It has been found out from practices that "task-based teaching is one of the most effective methods for English language students to participate as the subject” (Sun, 2013: 84). In recent years, task-based teaching, as a new teaching philosophy and method, has been gradually recognized and accepted by English language educators and teachers in China. This teaching philosophy advocates the teaching principle of "meaning supreme, application supreme" based on students as the subject, and requires learners to complete the task of purposefully communicating using the target language. The task-based teaching model is a challenge for teachers in teaching and students in learning, which requires teachers to shift their role from a knowledge initiator to the designer, organizer and instructor of classroom activities and students to shift from a passive listener to an active participant. The task-based teaching method is of great inclusiveness to other teaching methods, and compatible with various activities, which cover not only language activities, but also activities for learning language skills and knowledge; and is available for independent operation as well as beneficial to cooperative learning.

\section{Task-Based Teaching Practices and the Results}

The thought of task-based teaching is that to start from text reading, elaborately design the teaching program to fully arouse students' enthusiasm in participation, and gradually form the teaching model of subject participation in English course- i.e., to increase students' ability to understand and train their reading skills by designing small tasks designed for each link of the reading process and guiding them to successfully complete these tasks, and ultimately cultivate their reading comprehension. The New Outline has pointed out that one of the most important tasks of English course is to enable 
students to develop favorable learning habits and form effective learning strategies. To enable students to think in query and solve doubts, it is essentially necessary to carefully analyze and restructure the teaching materials, and elaborately set questions therein. It shall become a key point in lesson planning to tactfully create students' needs for proposing questions and stimulate them to put forward questions by utilizing their curiosity.

The reading strategies below are mainly adopted in the process of teaching.

\begin{tabular}{|l|l|l|}
\hline \multirow{4}{*}{$\begin{array}{l}\text { Metacognitive } \\
\text { strategies }\end{array}$} & Preparation in advance & $\begin{array}{l}\text { Browsing the article for the general idea and intention etc. } \\
\text { (Skimming or scanning) }\end{array}$ \\
\cline { 2 - 3 } & Attention to selection & $\begin{array}{l}\text { Looking for the required information through key words, } \\
\text { article identifiers etc. (Skipping) }\end{array}$ \\
\cline { 2 - 3 } & Self-management & $\begin{array}{l}\text { Adapting his/her own reading strategies to different reading } \\
\text { tasks }\end{array}$ \\
\cline { 2 - 3 } & Self-monitoring & $\begin{array}{l}\text { Correcting his/her own speculations and deductions from the } \\
\text { reading through self-monitoring }\end{array}$ \\
\cline { 2 - 3 } & Self-evaluation & Evaluating his/her own learning condition \\
\hline \multirow{4}{*}{$\begin{array}{l}\text { Cognitive } \\
\text { strategies }\end{array}$} & Deduction & $\begin{array}{l}\text { Using the context to deduce word meanings, sentence } \\
\text { meanings, the general intention of the article etc. }\end{array}$ \\
\cline { 2 - 3 } & Association of ideas & $\begin{array}{l}\text { Using the background knowledge and common sense to } \\
\text { speculate word meaning, sentence meaning, article general } \\
\text { intention etc. }\end{array}$ \\
\cline { 2 - 3 } & Expansion & $\begin{array}{l}\text { Using the learned knowledge of target language to understand } \\
\text { new words and sentences }\end{array}$ \\
\cline { 2 - 3 } & Transfer & Using the knowledge of mother language for comprehension \\
\cline { 2 - 3 } & Conclusion & Concluding the information comprehended in reading \\
\hline \multirow{3}{*}{$\begin{array}{l}\text { Social \& } \\
\text { Emotional } \\
\text { Strategies }\end{array}$} & $\begin{array}{l}\text { Cooperation } \\
\text { the purpose of } \\
\text { clarification }\end{array}$ & Seeking for explanation or clarifying doubts \\
\cline { 2 - 3 } & Self-soothing & Self conquering the anxiety involved in learning \\
\hline
\end{tabular}

\section{Cognition and Conclusion}

Advantages of this teaching mode: From the teaching concept, it regards students as the subject of active cognition and self-development; from the teaching purpose, it emphasizes on achieving the unification of intelligence and ability development through giving full play to students' subject function; from the teaching method, it pays attention to the research on teaching method as well as the methods for students to independently study; from the teaching process, it stresses the unified design and implementation of classroom teaching and off-class guidance; from the pattern of teaching activity, its emphasis is put on group cooperation, individual learning, brainstorming and other methods, to provide more time and space for students to participate; and from the teacher-student relationship, equality, harmony and co-participation are prioritized for the mutual development of teaching and learning.

It has been sincerely realized through our practices that this teaching method is of great practicality, and can make students' participation in class neither simple echoing nor the interaction between a fraction of students and the teacher, but "the active participation of all the students in class in thinking” (Sun, 2013: 103). It mobilizes the enthusiasm and initiative of all students to participate in classroom teaching, make their participation in classroom a real thinking activity, develops their learning strategy, cultivates their spirit of innovation and command of language, and deepens the participation in class. 


\section{Questioning at Class to Give Full Play to Students’ Subject Function}

\section{Proposal of Questions}

There is a popular saying in the education field in the early $20^{\text {th }}$ century that "knowing what questions to ask equals knowing how to teach”. It is obvious that proposal of questions plays a significant role in classroom teaching. It is a good method to set up question situations, and organize and regulate classroom teaching based on questions. However, in question setting attention shall be given to the following aspects: if a question contains too much information, students don't know where to start and what to do; if a question is too difficult and beyond the students' cognitive level and comprehension, students cannot give a solution in a short term and was therefore daunted; and they may also feel bored and less motivated to discuss if a question is too easy and the answer handy. According to Watkins (2005: 89), 'effective questions designed for class can stimulate students' desire for knowledge to a strong level, induce students' enthusiasm of thinking, and promote the internalization of their knowledge", allowing them to grasp the direction and way of thinking and become the master of learning and the subject of class.

\section{Implementation of Teaching Tasks and Results}

Refining Language. Refining means teaching with emphases, proper words and concise and non-wordy expressions to meet the standards and requirements of modern Chinese. Shakespeare, the great master of language, once said, "Brevity is the soul of wit." Questions shall be set with a vivid and concise language to induce students to think. The results of students' thinking may be affected if the length or difficulty of the question is improper, multiple complicated questions are put forward concomitantly, or questions are asked as a formality only. Before asking any question in the classroom, the teacher should select words to put forward a question using the most refined and logical language.

The use of figurative language may reduce the difficulty in question comprehension, and help students to understand the question profoundly and grasp the essence once they hear a question, without bothering the teacher to repeat, or bothering the students to ask "What do you mean?" or "I can't get it". Abstract concepts in a question shall be given certain emphasis on the crucial points and appropriately modified to clarify the cruxes of the question.

\section{Starting from the Actual Situation to Put Forward Effective Questions and Stimulate Students' Interest.}

Students' interest and inquisitiveness are the motive power for their active thinking. Only when students' interest and inquisitiveness in chemistry are stimulated will they become the subject of learning and the master of classroom. Flexible use of everyday materials to design question scenarios and guide students to think not only an effective method to stimulate students' interest in learning, but also brings students into extensive living practice.

\section{Questions Put Forward by Teachers shall be Divergent and All-inclusive.}

Divergent thinking is a thinking mode used to think from different directions and angles for exploring solutions from multiple aspects. Proposal of such questions opens up spaces for students' thinking activities to shift their thinking from a static and focal model to a dynamic and three-dimensional one, fosters the high-efficient way of thinking in a multisystemic, multidimensional, multifunctional, multiangular and multipath manner, and promote the extensity, height and globality of their thinking. Among the many questions teachers asked in teaching, some were found to be the "gap-filling" type, which divides profound and exploratory questions into several small subquestions that do not require students to think independently but to make simple answers easy to obtain, like "yes” or "no".

This requires teachers to prepare "some time-efficient questions in accordance with the teaching materials and based on current affairs, to arouse students' enthusiasm and initiative” (Sun, 2013: 114), and stimulate them to participate in the teaching activity to the maximum. In this way, students can be 
encouraged to use their brains and hands to act and explore, and make the learning activities under their independent control. Meanwhile, group activities can promote teacher-student and inter-student interactions and other interactive activities. Classmates' statements can inspire students to develop their own thinking, which makes group activities more conducive to improving the overall quality of students by expanding the teaching process from a cognitive process to a communication and developing process.

\section{Starting from the Connotation of Knowledge to Set Effective Question Groups and Activate Students' Thinking.}

The question group is composed of several questions, which shall be inspiring, able to induce students to think deeply and cultivate their ability to draw inferences about multiple cases from another instance. Based on a thorough grasp of the teaching materials and students, teachers shall center on the teaching target, and reflect the key and difficult points of the teaching materials by dividing one question into several sub questions to promote students to develop gradually and thereby realize the teaching purpose.

Under this questioning mode, a question group shall be formed with sound and elaborate questions at multiple levels and from multiple angles to guide students to think deeply and attract students to actively utilize their brains and expand their scope of thinking.

This proposal mode sets questions sound and elaborate, from multiple levels and angles to form the question group, so as to guide students to think deeply and attract students to actively utilize their brains and expand their thoughts. It helps cultivate students' analogy ability and ability to discover and solve problems.

Classroom proposal of questions is the heart of teaching that drives students to think and directs their way of thinking. Favorable classroom questioning can activate the entire teaching activities, enable students to grasp knowledge, develop their ability and activate their thinking. It allows students to fully act as a master of the class, and thus improves inter-student communication and teacher-student communication, and promotes the teaching achievements to improve steadily.

\section{Conclusion}

The above mentioned points are only an attempt to reform the Intensive Reading teaching in ESL. As it has been discussed for many times that different teaching techniques would excel properly in different leaning contexts. This paper provides the possibilities of ESL teaching in various teaching environment. In fact, there is still a long way to go. It requires more time and attempts to truly improve the quality of teaching and perfect the teaching methods. However, we believe we can achieve it!

\section{References}

[1] Y. Z. Sun, English Reading Teaching and the Research of Critical Thinking Skills Cultivation, Foreign Language Teaching and Research Press, Beijing, 2013.

[2] W. Lou, Myths and Misconceptions about English Leaning, Guangming Daily Press, Beijing, 2012.

[3] P. Watkins, Leaning to Teaching English, Delta Publishing, England, 2005. 